\title{
ПОНЯТЬ “ВЕЛИКУЮ ТРАНСФОРМАЦИЮ СТОЛЕТИЯ"
}

() ЧЖАН ЮЙЯНЬ, 2020

ЧЖАН Юйянь, Ph.D. (Econ.), академик Китайской академии общественных наук, директор Института мировой экономики и политики Китайской академии общественных наук. Китайская академия общественных наук, Институт мировой экономики и политики, Китайская Народная Республика, 100732 Пекин, Цзяньгомэньнэй дацзе, д. 5 (yyzhang@cass. org.cn).

Чжан Юйянь. Понять "великую трансформацию столетия". Анализ и прогноз. Журнал ИМЭМО РАН, 2020, № 2, сc. 20-29. DOI: 10.20542/afij-2020-2-20-29

DOI: $10.20542 /$ afij-2020-2-20-29

УДК: 327

Статья поступила в редакцию 17.02.2020.

В 2018 г. председатель КНР Си Цзиньпин высказал важное суждение о текущей глобальной ситуации, заявив, что мир находится в состоянии "великой трансформации, невиданной за столетие". Этот тезис стал для автора отправной точкой в попытке проанализировать и понять сложный современный мир, выявить тенденции времени, дабы эффективно использовать возможности развития и успешно реагировать на вызовы. Трактовка“великой трансформации столетия" охватывает многие аспекты: сравнение изменений мощи великих держав, далеко идущее влияние научно-технического прогресса и сопутствующих ему многочисленных неопределенностей, повсеместное пробуждение сознания собственных прав народных масс, изменения структуры народонаселения, эволюцию международной валютной системы, распад и реконструкцию системы мультилатерализма, ослабление внутренней системы США и китайско-американскую "игру". В контексте "великой трансформации столетия" также нельзя упускать из поля зрения те факторы, которые не претерпели существенных изменений, чтобы в итоге выявить весь набор компонентов, составляющих международную среду будущего развития Китая.

Ключевые слова: Китай, США, глобализация, глобальное соперничество.

Всемирная история представляет собой непрерывный поток перемен. В XX В. человечество прошло через многие драматические события: две мировые войны, за которыми последовали холодная война, столкновение исламской и христианской цивилизаций, появление завораживающих воображение людей технических инноваций. Однако ныне наблюдаются еще более глубокие изменения, о которых председатель КНР Си Цзиньпин сказал: “Это лучший период развития Китая в современной истории, мир претерпевает невиданную за столетие великую трансформацию. Эти две тенденции становятся все более переплетенными, они способствуют друг другу" [1].

Происходящие ныне перемены окажут большее влияние на будущее человечества, чем все преобразования XX в. Прозвучавшее из уст Си Цзиньпина суждение о важности “великой трансформации столетия" вызвало бурную дискуссию в научных кругах Китая. Можно выделить несколько ключевых аспектов, помогающих раскрыть глубину происходящих перемен.

\section{ФУНДАМЕНТАЛЬНЫЙ СДВИГ БАЛАНСА СИЛ ВЕЛИКИХ ДЕРЖАВ}

Важнейшей переменной величиной "великой трансформации столетия" является изменение баланса сил между главными мировыми державами. За минувшее 20-30 лет постепенное накопление количественных изменений привело к качественному сдвигу. Есть 
много показателей, отражающих уровень могущества государства, среди которых наиболее комплексным и широко используемым остается экономическая мощь.

Темпы экономического развития Китая в последние 40 лет были невероятно быстрыми. В 1978 г. показатель ВВП на душу населения в КНР составлял лишь 200 долл. США. В 2018 г. он приблизился к 10 тыс. долл. США.

В последнее десятилетие скорость экономического роста страны значительно превзошла собственные китайские прогнозы. В 2005 г. рассчитанный по рыночному обменному курсу ВВП Китая не достигал половины ВВП Японии. В 2010 г. китайский ВВП обогнал японский, а в 2015 г. превысил его вдвое. При сохранении нынешних темпов роста в 2022 г. ВВП Китая может превзойти ВВП Японии втрое. 40 лет назад ВВП Китая составлял около 2/30 объема ВВП США, к 2018 г. это соотношение изменилось до 2/3. КНР быстрыми темпами догоняет Соединенные Штаты по размеру экономики, эти две страны все больше уходят вперед и отрываются от других государств. Полагаю, что именно здесь следует искать объяснение перемен, которые происходят в последнее время в китайско-американских отношениях [2].

Некоторые китайские эксперты рассматривают формирование соотношения 2 : 3 при пересчете объемов ВВП по текущему курсу как важнейший сигнал, возвещающий поворот к ухудшению отношений между двумя крупнейшими экономиками мира. Китай не первая страна, которая после завершения Второй мировой войны достигла уровня 2/3 ВВП США. До него сходного результата удалось добиться СССР и Японии. Но как только одна из этих стран приближалась к размеру экономики, достигающему 2/3 американской, США серьезно меняли политику по отношению к ней. Инструменты сдерживания таких государств и интенсивность предпринятых мер различались, но результаты четко видны. В 2018 г. дистанция экономик обеих стран от США была куда более значительной, чем в прошлом. Объем экономики Японии сегодня составляет менее 1/4 экономики США; а России - всего 1/14. Возможно, что это одна из причин, по которой фраза “ловушка Фукидида" быстро стала известна во всем мире [3].

\section{НАУЧНО-ТЕХНИЧЕСКИЙ ПРОГРЕСС: ДАЛЕКО ИДУЩЕЕ И МАЛОПРЕДСКАЗУЕМОЕ ВЛИЯНИЕ}

Одним из фундаментальных компонентов “великой трансформации столетия" является стремительный технический прогресс. В XXI в. глобальные научно-технические инновации порождают повседневные изменения технологического ландшафта. Молниеносные темпы развития Интернета и цифровых технологий вызывают цепную реакцию в сферах производства, логистики, распределения и занятости.

Автоматизация производства и конвейер в прошлом создали огромное количество новых рабочих мест для инженерного персонала. Однако современные цифровые технологии и "искусственный интеллект" способны уничтожать существующие рабочие места без создания новых. Откликом на эти проблемы стали размышления экономистов, среди которых Дарон Асемоглу, один из авторов книги “Почему нации терпят неудачу" [4]. По оценкам консалтинговой компании McKinsey, к 2030 г. 800 млн промышленных рабочих будут заменены роботами. Теоретически почти все рабочие места могут быть заменены по мере продолжающегося снижения расходов на использование "искусственного интеллекта".

Исследователи предупреждают, что технологический прогресс ведет к увеличению неравенства доходов внутри стран и остановке роста доходов наемных работников. С точки зрения теории новые технологии должны повысить производительность труда. Однако реальность оказалась совершенно противоположной. В XXI в. не только в развитых экономиках США, ЕС и Японии, но и на зарождающихся рынках наблюдается замедление темпов прироста производительности труда - и это несмотря на выделение огромных средств на исследования и разработки. Экономисты назвали это явление “парадоксом производительности", и оно вне всяких сомнений оказывает негативное воздействие на долгосрочный рост глобальной экономики. Быстрое развитие технологий также коренным образом изменяет характер и форму войны. По сообщению журнала The Economist, внедрение цифровых технологий в военной сфере привело к появлению наряду с реальными фронтами новых цифровых фронтов. 
Роботизированные автономные боевые системы разрабатывают и развертывают в большом количестве. Это не только полностью меняет наше традиционное понимание военной профессии, но и ставит ряд этических вопросов о том, может ли "интеллектуальное оружие" быть убийцей [5]. Проблемы "серой зоны", когда создание угрозы не ведет к эскалации и не вызывает серьезного возмездия, уже стали темой горячих споров среди военных экспертов. В подобных ситуациях трудно распознать и идентифицировать настоящего виновника, например, в случае кибератаки или подрывной пропаганды.

Быстрая интернетизация мира сильно повлияла на взаимоотношения государств в международной системе. Интернет содействует рассредоточению и разделению полномочий, но при этом наделяет значительной властью США и другие государства, доминирующие в Интернет-пространстве, предоставляя им по отношению к прочим возможности “панорамного обзора" (panopticons) и контроля над"точками удара" (strokepoints). Эти преимущества усиливают их и могут быть использованы гегемоном Интернета в качестве оружия [6].

\section{МАССОВОЕ ПРОБУЖДЕНИЕ ПРАВОСОЗНАНИЯ}

Среди очевидных результатов распространения Интернета - резкое снижение стоимости коммуникаций, значительное расширение контента и существенное увеличение скорости передачи данных. Это заметно облегчает доступ к информации, новым идеям и общению. Люди глубже осознают свои права и более четко представляют себе способы их защиты. Развитие информационных технологий вызывает повсеместное пробуждение осознания собственных прав у широких слоев населения, что придает мощный толчок общественным трансформациям.

В то же время в отдельных странах подъем популизма и национализма начинает оказывать влияние на политику и дипломатию. В Европе можно наблюдать непрерывное укрепление ультраправых в Италии. В Латинской Америке последователь "трампизма" занял пост президента Бразилии. С точки зрения исследователей мировой политики это тревожная тенденция.

Другим последствием цифровой эпохи становится фрагментация общества. В результате информационного взрыва в мире Интернета аудитория непрерывно получает огромный поток сведений, который она не в состоянии освоить и потому теряет к нему интерес. На этой основе возник "парадокс изобилия" (paradox of plenty) [7]. Интернет-пользователи предпочитают видеть и слышать информацию, соответствующую их собственным предпочтениям. По этой причине различные медиа-источники конкурируют друг с другом, оттачивая свои алгоритмы выбора для предоставления информации с высокой степенью адресной направленности. Даже фальшивые новости могут выглядеть убедительно, если они исходят от "хороших друзей" в Интернете.

Массовое движение "желтых жилетов" во Франции отразило ситуацию, в которой разные слои общества следуют лишь своим собственным воззрениям. Люди получают новости и обмениваются информацией внутри своей группы, что естественно ведет к недостатку коммуникации и взаимному непониманию. Когда спикер Палаты представителей США говорит, что желает видеть не импичмент Трампа, а его тюремное заключение, поляризация американского общества очевидна всем.

Популистские националистические партии и политики, стоят они у власти или находятся в оппозиции, являются естественным порождением роста осознания собственных прав рабочим классом, пострадавшим от негативных последствий глобализации и интернетреволюции. В будущем это осознание способно превратиться в источник глобального распространения популистского национализма. Возникнет ли длительный период неопределенности на переходном этапе от распада глобальной системы до ее замены? Это будет напрямую зависеть от степени развития популизма и национализма.

Человечество пережило две "сетевые" революции. Первая привела к распространению в Европе новых идей после изобретения Гутенбергом в 1440-х годах печатного станка с наборным шрифтом. Второй стала революция повышения взаимосвязанности человечества 
в 1970-х годах после изобретения компьютера и появления Интернета. В “Площади и башне” [8] Найл Фергюсон пришел к выводу, что победа на выборах Дональда Трампа, подъем ИГИЛ (запрещенной в России террористической организации. - Прим. переводчика) и глобальный финансово-экономический кризис 2008 г., подобно Великой французской революции, Американской революции и движению церковной Реформации, произошли в периоды расширения "сетей". Превращение связей в сеть грозит миру анархией.

\section{СЛОЖНЫЕ ИЗМЕНЕНИЯ СТРУКТУРЫ НАРОДОНАСЕЛЕНИЯ}

Демографические изменения можно разделить на возрастные и этнические. Во всех крупных развитых странах в различной степени происходит старение населения, особенно в Японии и Европе. Сходная тенденция начинает давать о себе знать и в некоторых растущих экономиках, включая Китай. Вместе со старением населения обострились проблемы устойчивости системы социального обеспечения, макроэкономической политики государства, поддержания баланса между сбережениями и инвестициями, политических взглядов и электоральной активности пожилых людей.

Одновременно многие развивающиеся страны сталкиваются с проблемой увеличения доли молодежи. В Африке, на Ближнем Востоке и в Индии наблюдается демографический взрыв. В некоторых странах от 40 до 50\% населения составляют люди моложе 25 лет, что неизбежно приводит к крайне высокой безработице среди молодежи. Быстрый рост населения может существенно ослабить социальную стабильность и повысить спрос на ресурсы.

Изменения в этнической или расовой структуре способны оказать прямое воздействие на социальную сплоченность страны, внутриполитическую стабильность и внешнюю политику. Согласно отчету, опубликованному в ноябре 2017 г. Исследовательским центром Пью (Pew Research Center) [9], число мусульман Евросоюза выросло с 19.5 млн в 2016 г. до 25.8 млн в 2017 г., что составляет 4.9\% населения ЕС. В случае умеренных темпов роста миграции это соотношение увеличится до 11.2\% в 2050 г. При высоких темпах роста миграции в 2050 г. мусульмане будут составлять $19.7 \%$ населения Германии.

Сегодня более половины рожденных в США детей не имеют европейских корней. $\mathrm{K}$ 2024 г. половина жителей страны в возрасте до 20 лет не будет относиться к белому населению. Учитывая эти статистические данные, нетрудно понять причину "мусульманского запрета", который Д. Трамп пытался навязать вскоре после своего прихода к власти, и его приверженности планам строительства стены, способной оградить США от наплыва мигрантов из Мексики.

Естественным результатом изменения этнической структуры населения является укрепление этнической идентичности. ЭрикДж. Хобсбаум, автор книги“Нации и национализм”, указывал, что одна из основных характеристик групповой или этнической идентичности состоит в том, чтобы определить, кто является "жертвами", а кто - "злодеями". Злодеи это те, кому следует отвечать за "наши" страдания. "Они" вызывают тоску, разочарование, беспокойство и чувство утраты. "Они" не принадлежат к "нашей" группе, "они" - чужие, и поэтому - “наши" враги [10].

Меньшинства, которые находятся в постоянном конфликте с окружением, склонны отвергать добрую волю и терпимость к другим группам. Возможно, часть политической мудрости иногда заключается в том, чтобы обеспечить наличие каких-либо врагов как единственной эффективной возможности объединения групп. Крайнее обострение этнической самобытности и конфликтности внутри одного государства и между государствами стали темой исследования "Столкновение цивилизаций и воссоздание мирового порядка" известного американского политолога Сэмюэля Хантингтона [11]. 


\section{ПОСЛЕВОЕННАЯ ДОЛЛАРОВАЯ МИРОВАЯ ФИНАНСОВАЯ СИСТЕМА НА ПЕРЕПУТЬЕ}

Новый импульс обрела диверсификация или “дедолларизация" международной валютной системы. Это явление привлекает в последние годы широкое внимание. По рыночному курсу масштаб экономики США оставляет $22 \%$ мировой экономики, по паритету покупательной способности - 15\%. Однако доля доллара в глобальных расчетах, резервах, ликвидности и финансовом капитале превышает 50\%. Профессор Джеффри Сакс отмечает в статье "Политика Трампа вытеснит доллар", что США получают много преимуществ от доминирующей роли доллара в качестве резервной валюты [12]. Они могут собирать непомерные сеньоражные резервы в долларах, избегать валютного риска, легко продавать банковские услуги другим странам мира, минимизировать стоимость финансовых транзакций, влиять на ценообразование на товары и оказывать значительное влияние на политику других государств, особенно тех, где широко используют доллар.

Появление евро и возросшая роль китайского юаня после финансового кризиса 2008 г. открыли путь к многообразию в международной валютной системе. Решимость многих крупных экономик покончить с зависимостью от доллара была подкреплена торговыми войнами Трампа, растущим дефицитом бюджета США и использованием Вашингтоном основанной на долларе системы расчетов SWIFT для мониторинга глобальной финансовой деятельности и применения экономических санкций.

В 2018 г. Турция начала распродавать активы в долларах США. Иран объявил, что будет оценивать свою нефть в евро, а не в американской валюте. Россия уже осознала, что доллар стал рискованным инструментом для проведения международных операций, в торговле энергоресурсами и сырьем она стала увеличивать долю евро, рубля и даже юаня. Стабильно растет количество номинированных в юанях фьючерсов на нефть на Шанхайской международной энергетической бирже. Использующая юань Китайская международная система межбанковских платежей (China Interbank Payments System, CIPS) уже вышла за первоначальные ограниченные рамки.

Реформы международной валютной системы являются постоянной темой на саммитах БРИКС. Договор о создании Пула условных валютных резервов стран БРИКС и появление Нового банка развития БРИКС привлекли к себе внимание остального мира. На этом фоне пять стран вполне могут запустить собственную криптовалюту. Инструмент поддержки торговых бирж (INSTEX) также является важным новым достижением. Он был создан Великобританией, Францией и Германией для обеспечения торговли с Ираном, эти страны используют евро для обхода санкций США.

В статье "Экономическая война выбора Трампа" в конце 2018 г. бывший председатель управления активами Goldman Sachs и бывший министр финансов Великобритании Джим О'Нил написал: “В какой-то момент статусу доллара как глобального средства платежа и резервной валюты может быть брошен вызов" [13]. Направление развития международной валютной системы напрямую влияет на статус доллара в качестве одного из столпов гегемонии США. Система также важна для глобальной экономической стабильности и долгосрочного роста экономики, и она непосредственно связана с судьбой выпущенных технологическими гигантами цифровых валют наподобие Libra.

\section{РАСПАД И РЕКОНСТРУКЦИЯ МНОГОСТОРОННЕЙ СИСТЕМЫ}

Один из симптомов наступления "великой трансформации столетия" - распад и реформирование существующего многостороннего порядка. Администрация Трампа вышла из Парижского соглашения по климату, Транстихоокеанского партнерства и Совета ООН по правам человека. Она расторгла ядерное соглашение с Ираном и Договор о ликвидации ракет средней и меньшей дальности с Россией. Администрация США поставила вопрос о выходе из Всемирной торговой организации, выступала с резкими нападками на НАТО и даже на ООН и ее структуры. Похоже, что Соединенные Штаты добровольно отказываются от послевоенного международного порядка, который они так тщательно выстраивали. 
Некоторые эксперты полагают, что причинами распада миропорядка стали долгосрочный провал демократической политической системы США, который ведет страну к ослаблению, быстрый рост Китая и возрождение России. Однако с точки зрения господствующих в мире либеральных теорий, формирование международных альянсов служит важной опорой нынешних достижений США - но теперь им угрожают унилатерализм и протекционизм Трампа [14].

С экономической точки зрения, в краткосрочной и среднесрочной перспективе в торговой войне нет победителя, а по ее итогам проигрывают обе стороны. По этой причине некоторые аналитики называют поведение Трампа иррациональным. Однако его политика имеет свою внутреннюю логику. За последние 40 лет ВВП США на душу населения вырос более чем на 50 тыс. долл. Одним из основных факторов этого роста стало активное участие Китая в процессе глобализации, в котором доминируют развитые страны. Поддерживающей основой этого процесса была международная система, которую США тщательно разрабатывали и выстраивали после Второй мировой войны. Основной причиной отказа США от международного уклада, принесшего им огромные выгоды, является появление новой державы - Китая, воспринятое как угроза американскому глобальному доминированию.

Размер страны является уникальным и жизненно важным фактором в международном соперничестве. Крупные державы не только преследуют экономические интересы, но и стремятся к политическому превосходству. Принципиальное различие между политикой и экономикой заключается в том, что с экономической точки зрения участники игры могут найти вариант обретения общей выгоды, тогда как в политике преобладают соперничество и расхождения между конкурентами.

Обострение глобальных проблем выявило расширяющийся дефицит глобального управления, что свидетельствует об объективной и насущной необходимости значительного усовершенствования международного порядка. Согласно обновленной версии Красного списка Международного союза охраны природы 2018 г. [15], из 100 тыс. учтенных биологических видов более 28 тыс. находятся под угрозой исчезновения. Это $28 \%$ всех учтенных видов. С 1970 г. количество позвоночных на планете сократилось на 60\%. Из-за чрезмерного вылова рыбы в Тихом океане сохранилось лишь $30 \%$ первоначальной популяции голубого тунца. Исследования также показали, что в настоящее время скорость исчезновения видов в 100-10 000 раз превышает норму.

Если на фоне этих небывалых проблем человечество откажется предпринимать коллективные действия и остановить массовое вымирание видов, тогда его собственное существование будет поставлено под угрозу из-за коллапса пищевой цепи. Именно здесь может крыться причина начала распада многостороннего порядка и непрерывного появления новых идей глобального управления. В качестве показательного примера строительства нового общего международного порядка можно воспринимать находящуюся в процессе институционализации китайскую инициативу “Пояса и пути”.

\section{ИНСТИТУЦИОНАЛЬНЫЙ УПАДОК АМЕРИКАНСКОЙ СВЕРХДЕРЖАВЫ}

Чарльз Каломирис указывает, что финансовый кризис 2008 г. продемонстрировал, насколько окостенелой и в некотором смысле разрушительной стала система США [16]. Ее подверженность финансовым кризисам и дефицит кредитования не случайны, это порождение политической конкуренции и торга. Банковская система США сформировалась в результате политических сделок. Именно целями участников политического процесса определяется банковская политика от выдачи банковских лицензий и создания филиалов до распределения кредитов, модели надзора и межбанковских отношений.

Лоуренс Лессиг в книге "America, Compromised" называет тревожащим фактором не отдельные злоупотребления, а пособничество коррупции со стороны американских институтов в целом, что в конечном итоге чревато для страны угрожающими последствиями [17]. Он считает, что институциональное устройство финансовых, юридических, медицинских, научных учреждений и СМИ подвержено воздействию ошибочных стандартов и стимулов. 
Они, в свою очередь, оказывают разлагающее влияние на другие отрасли. Проблема далеко не всегда кроется в эгоистичном поведении конкретных личностей.

Стивен Брилл утверждает, что Первая поправка к Конституции США позволила обеспеченным классам склонить чашу весов демократии в свою пользу. Справедливо ценимая приверженность Америки надлежащему процессуальному праву использовалась для того, чтобы помешать правительству обеспечить соблюдение правил безопасности труда, привлечь к ответственности корпоративных преступников и иным образом защитить незащищенных. Призванные укрепить демократию избирательные реформы ее подорвали. Искусный финансовый и правовой инжиниринг превратил экономику США из двигателя долгосрочного роста и общего процветания в казино с несколькими крупными победителями. Америка раскололась на два класса: защищенных и незащищенных. Защищенные превзошли по силе, подмяли под себя и парализовали правительство. Незащищенные были отброшены еще дальше, явка избирателей и уважение к основным институтам, в особенности к правительству, стали самыми низкими за полвека. Исследователь признал, что для тридцатилетних американцев шансы зарабатывать больше своих родителей сократились до $50 \%$ по сравнению с 90\% сорок лет тому назад [18].

Непотизм распространен в США шире, чем мы думаем. The Economist поведал, что возможность стать губернатором у сына губернатора штата в 600 раз больше, чем у среднестатистического бэби-бумера, а сын сенатора становится сенатором в 8500 чаще чем обычный человек [19].

Многое свидетельствует о том, что США движутся по пути превращения в государство с высоким уровнем социального обеспечения. Подавляющее большинство американцев поддерживают увеличение расходов на эти цели. При введении всеобщего медицинского страхования бюджетные расходы США на социальные нужды составят 48\% ВВП страны практически на уровне Швеции, являющей пример европейского государства всеобщего благосостояния. Многие беспокоятся, что это приведет к неуклонному снижению потенциала экономического роста США. Несмотря на недавний рост ВВП в течение 122 месяцев подряд побивший предыдущий рекорд, установленный в период с 1991 по 2001 гг. - за все это время американская экономика увеличилась на $25 \%$. Это намного ниже совокупного роста в 43\%, достигнутого за предшествующий период процветания.

\section{РОСТ НАПРЯЖЕННОСТИ МЕЖДУ КРУПНЫМИ ДЕРЖАВАМИ: ОГРАНИЧЕНИЕ И ВСТРЕЧНОЕ ПРОТИВОДЕЙСТВИЕ}

“Политика силы” традиционно выражается в использовании крупными державами любых инструментов ради подавления соперника, иногда ценой принесения в жертву собственных интересов. Глубинные причины современных изменений можно свести к одной: Китай стремительно развивает свои высокотехнологичные отрасли. Китайско-американские отношения пока не достигли стадии новой холодной войны. Политика США в отношении Советского Союза в годы холодной войны сводилась к сдерживанию и изоляции. Америка максимально избегала торговых или общественных контактов с СССР и его союзниками, желая чтобы низкая эффективность привела СССР на путь саморазрушения.

В отношении Китая во времена холодной войны и последующий период США проводили политику вовлечения. Она была призвана втянуть Китай в руководимую США международную систему, заставить его взять на себя определенные обязательства и таким образом перестроить КНР. Ныне в США звучат призывы к размежеванию с Китаем и, в конечном итоге, к политике сдерживания. Однако это невозможно, потому что изоляция Китая потребовала бы скоординированных действий всех основных экономик мира при поддержке большого числа развивающихся стран. К тому же в этом нет необходимости, потому что угроза Китая для США и других развитых стран исходит из возможности обогнать их в высокотехнологичных секторах, а не из конкуренции на средних и низших уровнях производства. Суть политики Вашингтона в отношении Пекина заключается в том, чтобы продолжать пользоваться преимуществами китайских поставок на среднем и нижнем уровнях глобальных цепочек создания стоимости, не допуская того, чтобы Китай вырвался вперед в высокотехнологичном секторе, особенно 
в цифровых технологиях. Эту фундаментальную политику в отношении КНР можно описать словом “ограничение" (кит. гуйсо 规锁, англ. confinement) [20].

Китайское слово состоит из двух иероглифов - “правила" (гуй) и “закрытие” (со). Политика ограничения преследует две цели. Первая - использовать новый набор международных правил, чтобы установить рамки и пределы действий Китая в высокотехнологичных секторах. Вторая цель заключается в том, чтобы "запереть" Китай в глобальных цепочках поставок с низкой стоимостью, сохранив или даже расширив его технологическое отставание от США. Частое применение Вашингтоном американского внутреннего законодательства к своим торговым партнерам мотивировано главным образом тем, что многосторонняя система не может ограничивать Китай, как того хотели бы США.

Наиболее очевидным примером является "Специальный отчет 301", опубликованный торговым представителем Соединенных Штатов в марте 2018 г. [21]. Этот документ полностью посвящен вопросам, связанным с пресловутыми проблемами кражи технологий, их принудительной передачи и защиты интеллектуальной собственности. Сходный замысел лежит в основании совместного заявления США, ЕС и Японии, призывающего к реформе правил ВТО и выдвигающего требования прозрачности со стороны правительства Китая в отношении субсидий. В сообщении Bloomberg News 26 мая 2019 г. было сказано, что "цифровой "железный занавес" заставит политических лидеров выбирать между Китаем и США" [22]. Иными словами, состязание между американской стратегией "ограничения" и китайской стратегией "сопротивления ограничению" стало современной формой "ловушки Фукидида", и она уже оказывает влияние на международную ситуацию в целом.

\section{ВИДЕТЬ НЕИЗМЕННОЕ В ПОТОКЕ ПЕРЕМЕН}

Изменение всегда содержит в себе неизменное, в постоянстве содержатся семена перемен. Взрыв первой атомной бомбы стал поворотным моментом человеческой истории. В книге "Почему Запад господствует - пока еще" [23] Иэн Моррис отмечает, что ни великие люди, ни глупцы не могут изменить ее ход, им под силу лишь ускорить либо притормозить исторический процесс. Однако после 1945 г. политические лидеры смогли изменить историю. В прошлом последствиями людской ошибки могли быть упадок или распад общества. Теперь ошибка может привести к полной гибели человечества.

Со времени вступления планеты в ядерную эпоху ничего не изменилось. По оценкам Стокгольмского международного института исследований проблем мира (SIPRI), в мире сейчас насчитывается более 15850 ядерных боеголовок [24]. У США и России их около 6550 и 6850 соответственно. Этого достаточно, чтобы десятикратно уничтожить все население планеты, которое продолжает жить в тени страха ядерной смерти. Ядерное оружие накладывает жесткий верхний предел на любой конфликт между США и Россией либо США и Китаем, потому что тотальная война между ядерными державами ничем не отличается от истребления.

Еще одна неизменная константа современного мира - это огромная степень взаимозависимости между странами и регионами. Эта взаимозависимость выражается в высоком уровне международной специализации и глубоких торговых связях, охватывающих весь мир. В статье "Пять мифов о глобализации" [25] Стивен Альтман предложил доказательства того, что глобализация, измеряемая потоками торговли, капитала, информации и людей, выросла до рекордно высокого уровня в 2017 г. Мир тесно связан в глобальных цепочках поставок и стоимости. Хотя "системные интеграторы" [26], занимающие самые высокие позиции в цепочке создания стоимости, по-прежнему сосредоточены в США, Европе и Японии, издержки разъединения между основными развитыми и развивающимися странами возросли до уровня, который мир себе позволить не может. Каждой стране получаемые от торговли выгоды помогают ослабить неизбежную внутреннюю общественную и политическую реакцию, сводя на нет антиглобалистские устремления.

В целом тенденция глобализации не прерывалась, но столкнулась с временными трудностями. Экономическая глобализация является важным этапом исторического процесса, она не всегда продвигается спокойно, плавно и по прямой линии. Процесс глобализации 
неизбежно сопровождается ухабами и поворотами, к ним можно отнести проводимую администрацией Трампа политику унилатерализма, протекционизма и запугивания других стран.

\section{ОГЛЯНУТЬСЯ НА ВЕЛИКУЮ ТРАНСФОРМАЦИЮ ЧЕРЕЗ СТОЛЕТИЕ}

Через сто лет, когда историки оглянутся назад на нынешний период развития человечества, они, скорее всего, обобщат "вековые перемены" как "возрождение Востока в лице Китая и ответные меры на возрождение Востока со стороны с Запада во главе с США". Китай и США - это две крупные державы. Одна стремительно растет, другая - с усталостью цепляется за статус сверхдержавы. Одна стремится обрести глобальное влияние, соответствующее ее мощи, другая совершенно не желает делиться властью с иными государствами. Одна придерживается древних политических и культурных традиций Востока, другая является продуктом западной цивилизации и христианского воспитания. Вполне естественно и нормально, что между этими державами есть расхождения, трения и даже - в определенной степени - столкновения.

Вместе с тем решение многих глобальных проблем в интересах всего человечества требует сотрудничества двух крупнейших государств мира в лице КНР и США. Они должны совместно взять на себя ответственность за поиски ответа на общемировые вызовы. Необходимая исходная предпосылка состоит в том, чтобы Китай и Соединенные Штаты нашли мудрость и смелость для того, чтобы во время борьбы решать возникающие между ними недоразумения, противоречия и конфликты.

\section{СПИСОК ЛИТЕРАТУРЫ / REFERENCES}

1. 坚持以新时代中国特色社会主义外交思想为指导 努力开创中国特色大国外交新局面”，《人民日 报》，2018年6月24日，第1版 [Guided by the Socialist Diplomatic Thought with Chinese Characteristics in the New Era, Strive to Create a New Situation for the Diplomacy among Major Powers with Chinese Characteristics. Peopless Daily, 24.06.2018 (In Chin.)]

2. 张宇燕: “跨越大国赶超陷阱”，《世界经济与政治》，2018年第1期, 第1页 [Zhang Yuyan. Overcoming the Thucydides's Trap. World Economic and Politics, 2018, Iss. 1. P. 1. (In Chin.)]

3. Graham A. Destined for War: Can America and China Escape the Thucydides's Trap? Boston, Houghton Mifflin Harcourt, 2017. 384 p.

4. Acemoglu D., Robinson J.A. Why Nations Fail. New York, Crown Publishers, 2012. 571 p.

5. Salisbury P. Autonomous Weapons and the New Laws of War. The Economist, 19.01.2019. Available at: $\quad$ https://www.economist.com/briefing/2019/01/19/autonomous-weapons-and-the-new-laws-of-war (accessed 17.02.2020).

6. Farrell H., Newman A.L. Weaponized Interdependence: How Global Economic Networks Shape State Coercion. International Security, 2019, vol. 44, no.1, pp. 42-79.

7. Nye J. American Soft Power in the Age of Trump. Project Syndicate, 06.05.2019. Available at: $h$ ttps:// www.project-syndicate.org/commentary/american-soft-power-decline-under-trump-by-joseph-s-nye-201905?barrier=accesspaylog (accessed 17.02.2020).

8. Ferguson N. The Square and Tower: Networks, Hierarchies and the Struggle for Global Power. New York, Penguin Books, 2018. 573 p.

9. Hackett C. 5 Facts about the Muslim Population in Europe. Pew Research Center, 29.11.2017. Available at: $\quad$ https://www.pewresearch.org/fact-tank/2017/11/29/5-facts-about-the-muslim-population-in-europe/ (accessed 17.02.2020).

10. Hobsbawm E.J. Nations and Nationalism since 1780: Programme, Myth, Reality (Canto Classics). Cambridge, Cambridge University Press, 2012. 218 p.

11. Huntington S. The Clash of Civilizations and the Remaking of World Order. New York, Simon and Schuster, 1996. $353 \mathrm{p}$.

12. Sachs J.D. Trump's Policies Will Displace the Dollar. Project Syndicate, 03.09.18. Available at: $\underline{h t t p s: / /}$ www.project-syndicate.org/commentary/trump-policies-undermining-the-dollar-by-jeffrey-d-sachs-201809?barrier=accesspaylog (accessed 17.02.2020).

13. O'Neill J. Trump's Economic War of Choice. The Gulf Times, 15.12.2018. Available at: https://www.gulftimes.com/story/617002/Trump-s-economic-war-of-choice (accessed 17.02.2020).

14. Zakaria F. The Self-Destruction of American Power: Washington Squandered the Unipolar Moment. Foreign Affairs, 2019, July/August, vol. 98, no. 4, pp. 10-16.

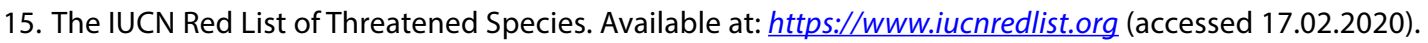

16. Calomiris C., Haber S. Fragile by Design: The Political Origins of Banking Crises and Scarce Credit. Princeton University Press, 2014. 570 p. 
17. Lessig L. America, Compromised. University of Chicago Press, 2018. 240 p.

18. Brill St. How Baby boomers Broke America. The Times, 28.05.2018. Available at: https://time.com/5280446/ baby-boomer-generation-america-steve-brill// (accessed 17.02.2020).

19. Cover Story: “Dynasties: The Power of Families”. The Economist, 18.04. 2015.

20. 张宇燕、冯维江：“从 “接触” 到 “规锁” : 美国对华战略意图及中美博弯的四种前景” , 《清华 金融评论》，2018年第7期，第24 25页 [Zhang Yuyan, Feng Weijiang. From Contact to Confinement: Four Prospects of the U.S. Strategic Intention towards China and the Bilateral Game. Tsinghua Financial Review, 2018, no. 7. (In Chin.)]

21. China Section 301-Tariff Actions and Exclusion Process. Office of the United States Trade Representative. Available at: https://ustr.gov/issue-areas/enforcement/section-301-investigations/tariff-actions (accessed 17.02.2020).

22. Culpan T. The Tech Cold War has Begun. Bloomberg, 20.05.2019. Available at: https://www.bloomberg. com/opinion/articles/2019-05-20/huawei-supply-freeze-points-to-u-s-china-tech-cold-war $\quad$ (accessed 17.02.2020).

23. Morris I. Why the West Rules--for Now: The Patterns of History, and What They Reveal About the Future. New York, Picador, 2011. $768 \mathrm{p}$.

24. SIPRI Yearbook 2018. Available at: https://www.sipri.org/yearbook/2018 (accessed 17.02.2020).

25. Altman S. Five Myths about Globalization. Washington Post, 12.02.2019.

26. Nolan P. Is China Buying the World? Cambridge (UK), Malden (MA, USA), Polity Press, 2013. 120 p.

\title{
UNDERSTANDING THE "GREAT TRANSFORMATIONS OF A CENTURY"
}

\section{(Analysis and Forecasting. IMEMO Journal, 2020, no. 2, pp.20-29)}

\author{
Received 17.02.2020.
}

ZHANG Yuyan (yyzhang@cass.org.cn),

Institute of World Economics and Politics, Chinese Academy of Social Sciences, 15th Floor, CASS Building, no. 5, Jianguomennei Dajie, Beijing 100732, P.R. China.

In 2018 President Xi Jinping made an important judgment on the current global situation, that is, the world is in a state of unprecedented change in a century. This judgment is the starting point for the author to analyze and grasp the complicated world at this stage, follow the trend of the times, make good use of development opportunities, and successfully respond to challenges. The understanding of the century-old change can be seen from the comparison of changes in the strength of the great powers, the far-reaching impact of scientific and technological progress and the numerous uncertainties, the general awakening of people's rights, the change in the population structure, the evolution of the international monetary system, the collapse and reconstruction of the multilateral system, the weakness of the US internal system and The Sino-US game has intensified in eight dimensions. In the context of a century of change, special attention should also be paid to those factors that have not changed significantly. It is these "changes" and "unchanged" that constitute the international environment for China's future development.

Keywords: China, USA, globalization, global competition.

About the author:

ZHANG Yuyan, Ph.D (Econ.), Academician of the Chinese Academy of Social Sciences, Director of the Institute of World Economics and Politics, Chinese Academy of Social Sciences.

DOI: 10.20542/afij-2020-2-20-29 